
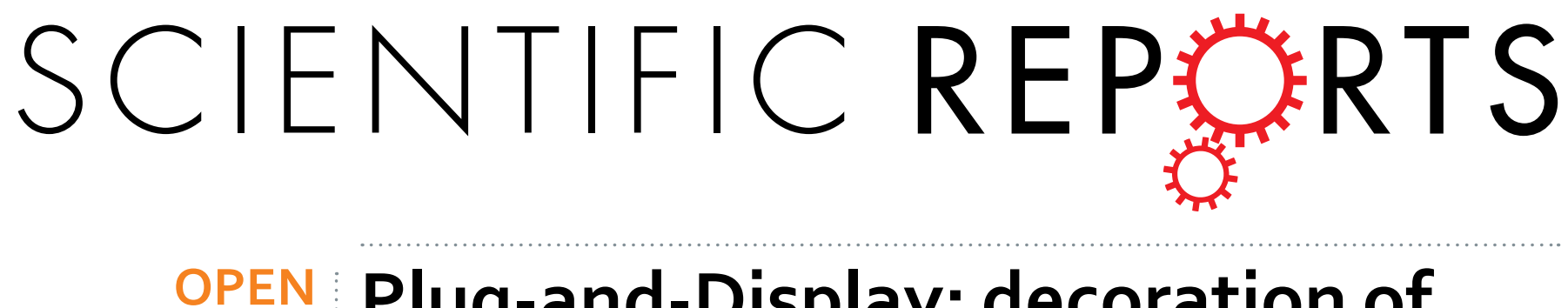

\title{
Plug-and-Display: decoration of Virus-Like Particles via isopeptide bonds for modular immunization
}

Received: 08 October 2015

Accepted: 09 December 2015

Published: 19 January 2016

\section{Karl D. Brune ${ }^{1}$, Darren B. Leneghan², Iona J. Brian², Andrew S. Ishizuka², Martin F. Bachmann ${ }^{2,3}$, Simon J. Draper ${ }^{2}$, Sumi Biswas ${ }^{2} \&$ Mark Howarth $^{1}$}

Virus-like particles (VLPs) are non-infectious self-assembling nanoparticles, useful in medicine and nanotechnology. Their repetitive molecularly-defined architecture is attractive for engineering multivalency, notably for vaccination. However, decorating VLPs with target-antigens by genetic fusion or chemical modification is time-consuming and often leads to capsid misassembly or antigen misfolding, hindering generation of protective immunity. Here we establish a platform for irreversibly decorating VLPs simply by mixing with protein antigen. SpyCatcher is a genetically-encoded protein designed to spontaneously form a covalent bond to its peptide-partner SpyTag. We expressed in E. coli VLPs from the bacteriophage AP205 genetically fused to SpyCatcher. We demonstrated quantitative covalent coupling to SpyCatcher-VLPs after mixing with SpyTag-linked to malaria antigens, including CIDR and Pfs25. In addition, we showed coupling to the VLPs for peptides relevant to cancer from epidermal growth factor receptor and telomerase. Injecting SpyCatcher-VLPs decorated with a malarial antigen efficiently induced antibody responses after only a single immunization. This simple, efficient and modular decoration of nanoparticles should accelerate vaccine development, as well as other applications of nanoparticle devices.

Virus-like particles (VLPs) are self-assembling multi-protein particles that mimic the structural organization and conformation of viruses. VLPs enable both surface display as well as payload encapsulation, providing versatility as biomedical research tools and vaccines ${ }^{1,2}$. Vaccines are one of the most effective of all medical interventions but for many diseases, such as malaria, HIV and cancer, vaccination has still had limited success ${ }^{2,3}$. Also, a rapid cycle of development, testing and production of new vaccines is required to deal with emerging pandemic viral threats ${ }^{4}$. Display on VLPs greatly enhances the response to otherwise poorly immunogenic epitopes ${ }^{5,6}$, because of a number of key characteristics. The dense protein arrangement of VLPs strongly triggers B-cell receptor clustering ${ }^{6,7}$. The 20-200 nm size of VLPs facilitates direct drainage to lymph nodes, increasing uptake by antigen-presenting cells and cross-presentation ${ }^{6,8}$. Also, the RNA or DNA packaged in VLPs triggers costimulatory signals through Toll-like receptors TLR3/7/8/9,8. VLPs can be conveniently produced at high quantities and commercial scale through heterologous recombinant gene expression in a range of expression systems, including Escherichia coli, tobacco and yeast species ${ }^{9}$. VLPs are in use or under development to vaccinate against bacterial, viral and protozoal pathogens ${ }^{3,10,11}$, as well as against chronic diseases (autoimmunity, allergy, neurodegenerative diseases and (ancer) $)^{12-14}$.

Display of antigens on VLPs is usually achieved by either chemical conjugation or genetic fusion to the viral coat protein ${ }^{1,15}$. Genetic fusion has been successful in numerous examples but remains a time-consuming trial-and-error approach ${ }^{16}$. Genetic fusion of certain antigens leads to misfolding of the antigen or the capsid; this misfolding either impairs VLP assembly or stability, or leads to the display of antigen in a non-native conformation, so that the antibodies raised are ineffective ${ }^{15,17,18}$. Another major challenge with genetic fusion is that the host optimal for VLP expression and the host optimal for antigen expression (bacterium, yeast, mammalian cell-line, or plant) may have different post-translational modifications (particularly disulfide bond formation and glycosylation $)^{15,19}$.
${ }^{1}$ Department of Biochemistry, University of Oxford, South Parks Road, Oxford, OX1 30U, UK. ${ }^{2}$ Jenner Institute, University of Oxford, Oxford, OX3 7DQ, UK. ${ }^{3}$ University Institute of Immunology, University of Bern, Sahli Haus 2, Inselspital, Bern, CH-3010, Switzerland. Correspondence and requests for materials should be addressed to M.H. (email: mark.howarth@bioch.ox.ac.uk) 


\section{SpyCatcher AP205 CP3}

Expression in E. coli

\& self-assembly

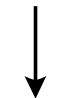

SpyCatcher-VLP

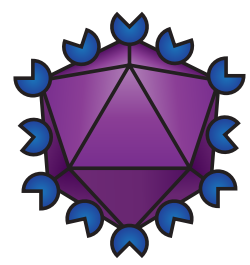

Mix with SpyTag-Antigen

$\infty$

$\searrow$ spa SpyTag-Ag 2

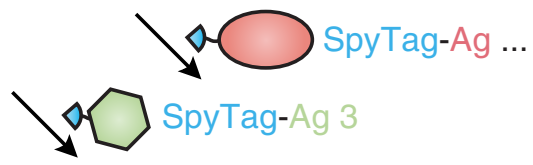

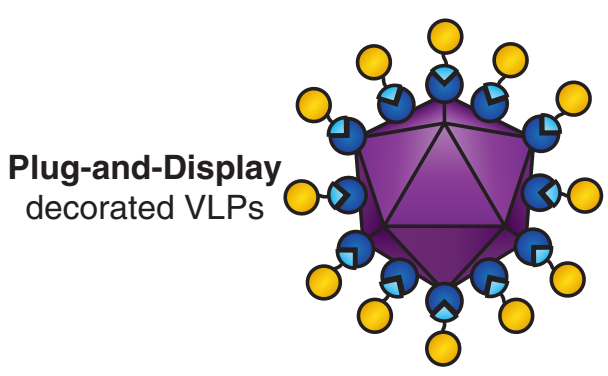

Immunize

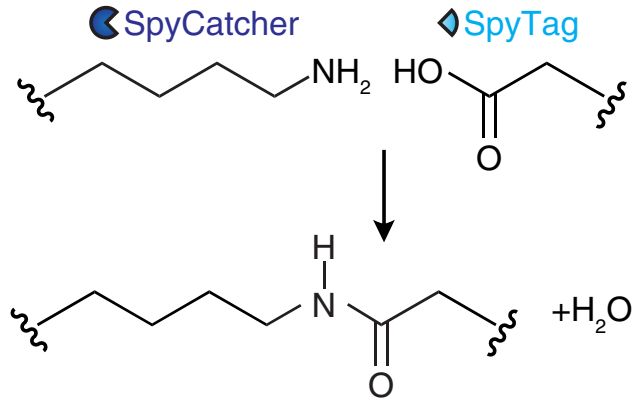

Spontaneous isopeptide bond formation

Figure 1. Overview of Plug-and-Display VLP assembly. SpyCatcher is genetically fused to the AP205 phage coat protein (AP205 CP3) and expressed in E. coli. Self-assembly of monomers generates SpyCatcher-VLPs. Upon mixing, SpyTag-antigen forms a spontaneous isopeptide bond with SpyCatcher-VLPs, yielding decorated particles for immunization.

Therefore, separately expressing the VLP and target antigen is often preferable or necessary; subsequently the VLP and target antigen must be linked together. Conjugation through the abundant amino groups (Lys, $\mathrm{N}$-terminus) or carboxyl groups (Asp, Glu, C-terminus) gives a heterogeneous mixture, so conjugation through an exposed sulfhydryl group (Cys) on the antigen is the most common route ${ }^{19,20}$. Chemical conjugation may give limited control over the number of VLP modifications, leading to heterogeneous and incomplete VLP coverage with antigen ${ }^{18,21}$. Also, many surface-exposed antigens of pathogenic or human origin contain disulfide bonds, which play an important role in protein folding and stabilization, so a new cysteine can be disruptive ${ }^{22,23}$.

Alternative routes to VLP functionalization include non-covalent VLP:antigen linkage, such as attaching Ni-NTA to VLPs for linkage of His-tagged antigens ${ }^{24}$ but the stability during storage and in the body may be an issue. Glycosylphosphatidylinositol (GPI)-anchored proteins can be expressed in one cell-type and then transferred into VLPs, although this is restricted to VLPs containing a lipid bilayer and the purification of the GPI-linked proteins is non-trivial ${ }^{14}$.

Unnatural amino acids may be incorporated into the VLP and antigen for click chemistry conjugation ${ }^{25-27}$, enabling site-specific modification and stable linkage, but the increased complexity of protein expression, side-reactions of certain azide/alkyne/tetrazine groups ${ }^{28-30}$ and the increased frequency of misreading of 
a

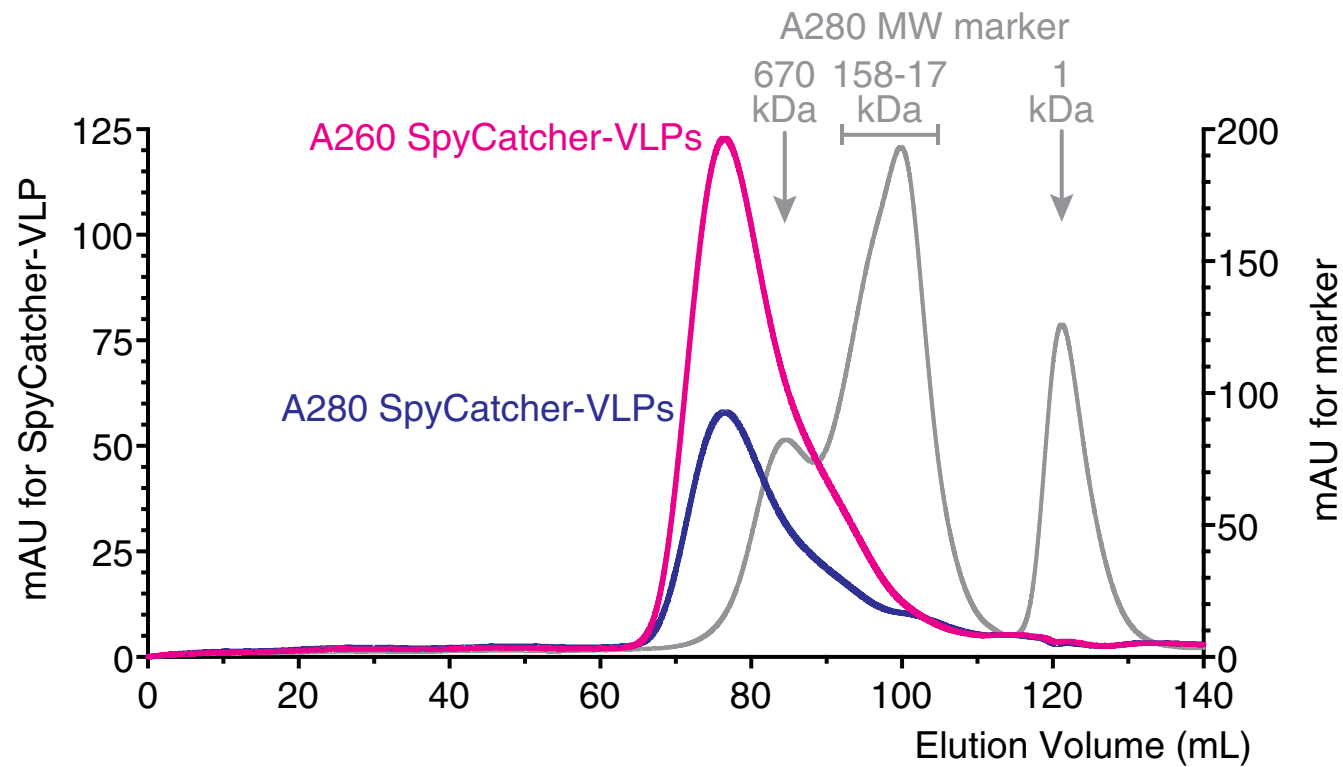

b

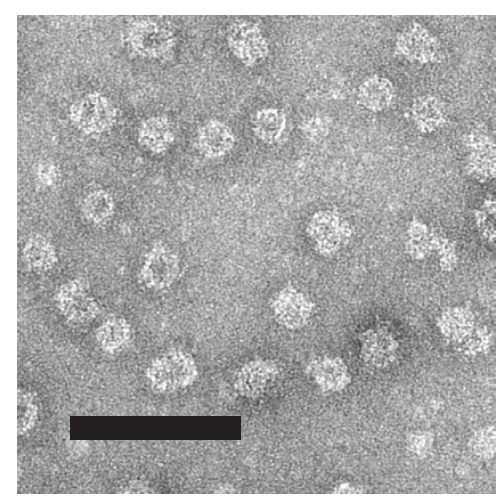

C

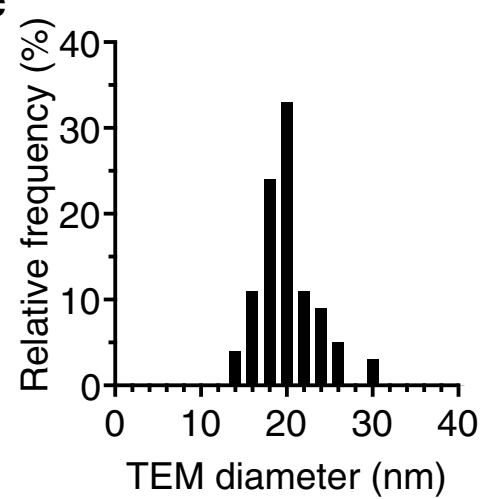

Figure 2. Characterization of SpyCatcher-VLP assembly. (a) Size-exclusion chromatography showed SpyCatcher-CP3 assembly into VLPs, analyzed by absorbance at 260 and $280 \mathrm{~nm}$ and compared to Mw markers. (b) Negatively-stained TEM image of SpyCatcher-VLPs. Scale bar $100 \mathrm{~nm}$. (c) Size distribution of SpyCatcherVLPs from TEM $(\mathrm{n}=100)$.

unnatural amino acid codons ${ }^{31}$ mean that there is still a need for simple and scalable approaches for covalent VLP:antigen linkage.

To address this challenge, we made use of genetically-encoded spontaneous amide bond formation ${ }^{32}$. SpyTag is a peptide we previously engineered to form a spontaneous and irreversible isopeptide bond to its protein partner SpyCatcher simply upon mixing (Fig. 1) ${ }^{33}$. Both SpyTag and SpyCatcher can be positioned at various locations in protein chains, are reactive under a wide range of conditions ( $\mathrm{pH}$, buffer, temperature), and do not possess cysteines $^{33-35}$. Here we establish the use of SpyTag-SpyCatcher reactivity for modular VLP functionalization, characterizing SpyCatcher-linked VLPs, demonstrating conjugation to a range of different antigens, and showing effective immunization in mice.

\section{Results}

SpyCatcher-VLP expression and analysis. We genetically fused SpyCatcher to the N-terminus of the viral coat protein (CP3) of the RNA bacteriophage AP205 (Fig. 1) ${ }^{36,37}$. SpyCatcher-CP3 was expressed in E. coli and VLPs were purified to homogeneity from cell-lysate by Ni-NTA affinity chromatography and then by dialysis using a $300 \mathrm{kDa}$ molecular weight cut-off (MWCO) membrane. Size-exclusion chromatography showed the material eluting in the MDa range expected for VLPs, with concurrent elution of protein ( $280 \mathrm{~nm}$ absorbance) and nucleic acid species (260 nm absorbance), typical for AP205 VLPs (Fig. 2a) ${ }^{36,38,39}$. Negative-staining transmission electron microscopy (TEM) revealed the presence of particles consistent with VLPs (Fig. 2b). Quantifying the particle size from TEM gave a diameter of $20 \pm 3.2 \mathrm{~nm}$ (mean \pm 1 s.d., $\mathrm{n}=100)$ (Fig. 2c).

SpyCatcher-VLP covalent conjugation. For initial validation of SpyCatcher-VLP reactivity, we mixed the VLPs with the model SpyTag-linked protein, E. coli maltose binding-protein (MBP) ${ }^{33}$. SpyCatcher-CP3 gave a clean band on SDS-PAGE and after mixing with excess SpyTag-MBP, all the SpyCatcher-CP3 moved to a higher 
a

b

C

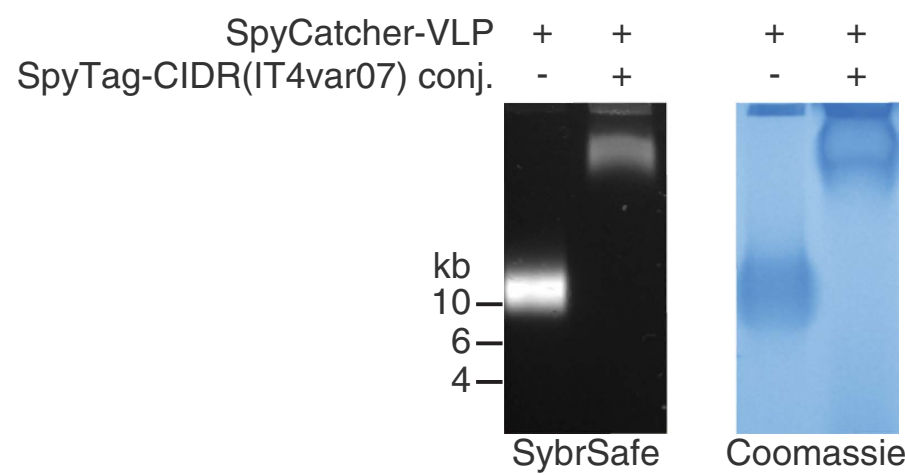

SpyTag-MBP + + - - -

SpyCatcher-VLP - + + + -

SpyTag DA-MBP - - - + +

SpyCatcher-VLP + - - + + +

SpyTag-CIDR(HB3varO3) - + - - + - -

SpyTag-CIDR(IT4var07) - - + - + -

Pfs25-SpyTag - - - + - +
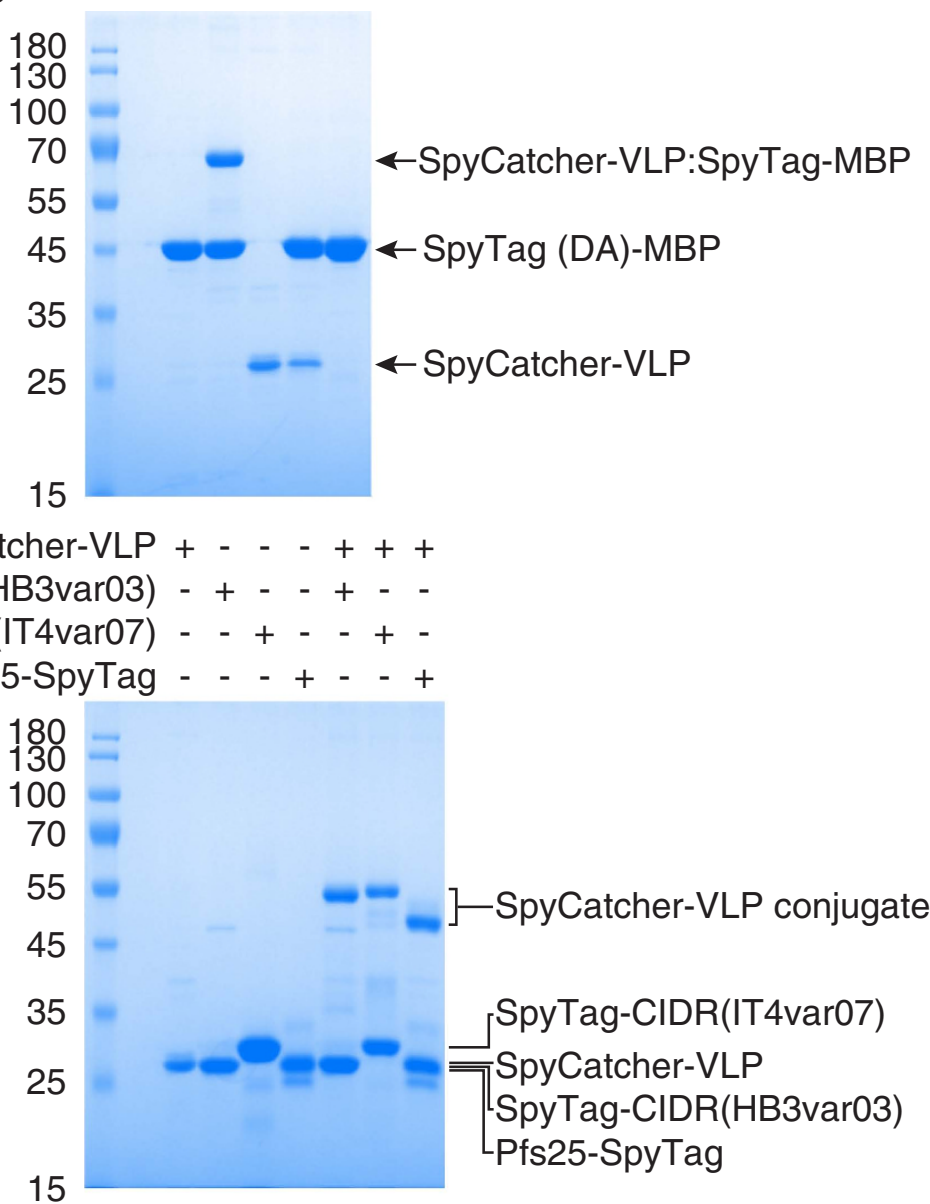

Figure 3. Decoration of VLPs by spontaneous isopeptide bond formation. (a) Complete reaction of SpyCatcher-VLPs with SpyTag. SpyCatcher-VLPs were incubated with SpyTag-MBP or the negative control SpyTag DA-MBP, before boiling in SDS-loading buffer and analysis by SDS-PAGE with Coomassie staining. (b) SpyCatcher-VLP reacted with malarial protein antigens. As in (a), except with SpyTag-CIDR(HB3var03), SpyTag-CIDR(IT4var07) or Pfs25-SpyTag. (c) Native agarose gel electrophoresis of VLPs. The gel was stained with SybrSafe (nucleic acid) and then Coomassie dye (protein), showing unconjugated SpyCatcher-VLPs and SpyCatcher-VLPs conjugated with SpyTag-CIDR(IT4var07).

molecular weight, consistent with quantitative covalent bond formation (Fig. 3a). The negative control SpyTag DA-MBP, with the reactive aspartic acid of SpyTag changed to alanine ${ }^{33}$, did not change SpyCatcher-CP3 mobility (Fig. 3a).

We then tested SpyCatcher-VLP decoration with immunologically-relevant antigens from Plasmodium falciparum. P. falciparum erythrocyte membrane protein 1 (PfEMP1) contains a Complex lysine and cysteine-rich Inter-Domain Region (CIDR). CIDR interaction with endothelial protein C receptor (EPCR) is associated with 

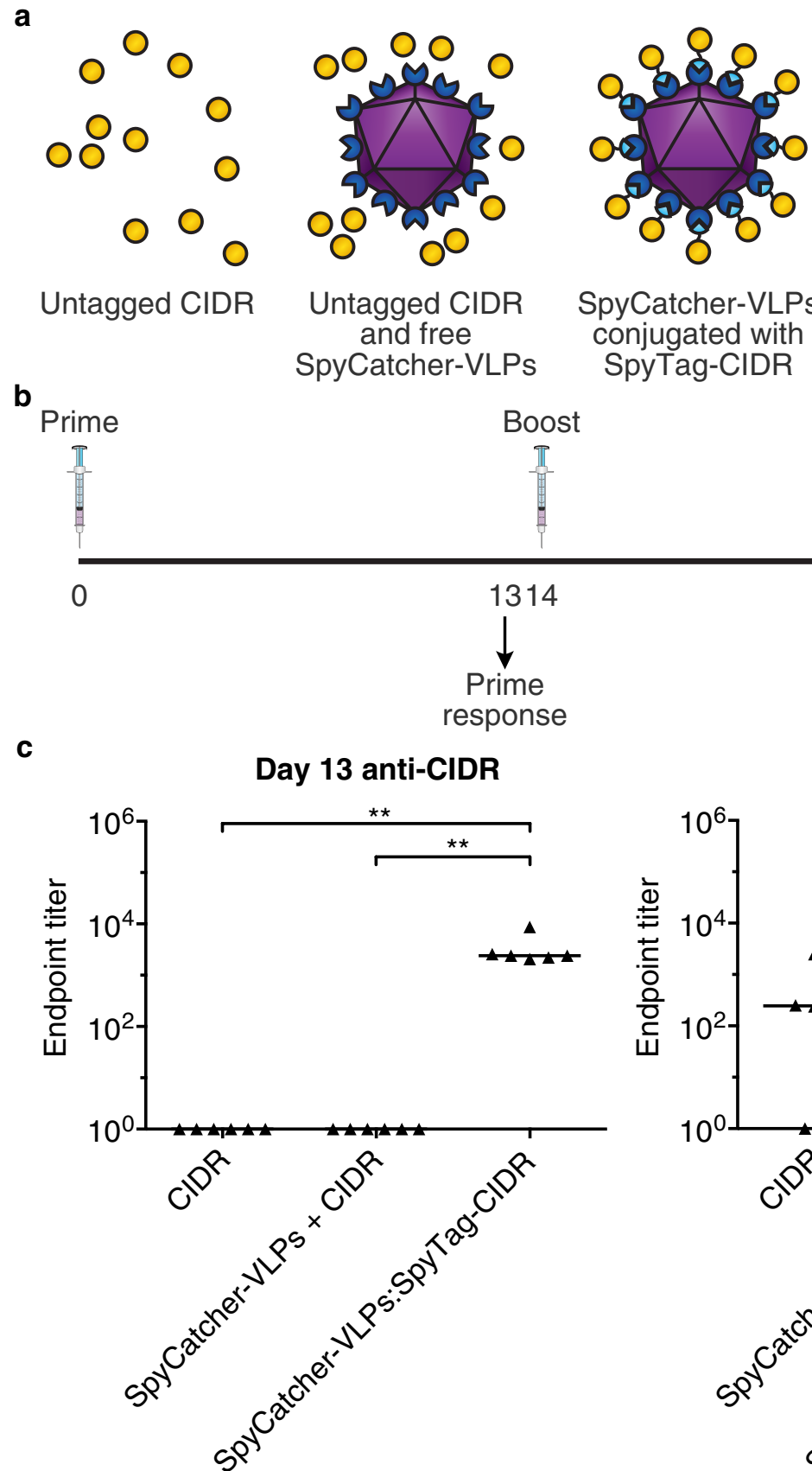

$$
\begin{aligned}
& \text { conjugated with } \\
& \text { SpyTag-CIDR }
\end{aligned}
$$

b

rime

Boost 
a

\section{Day 16 anti-Pfs25}

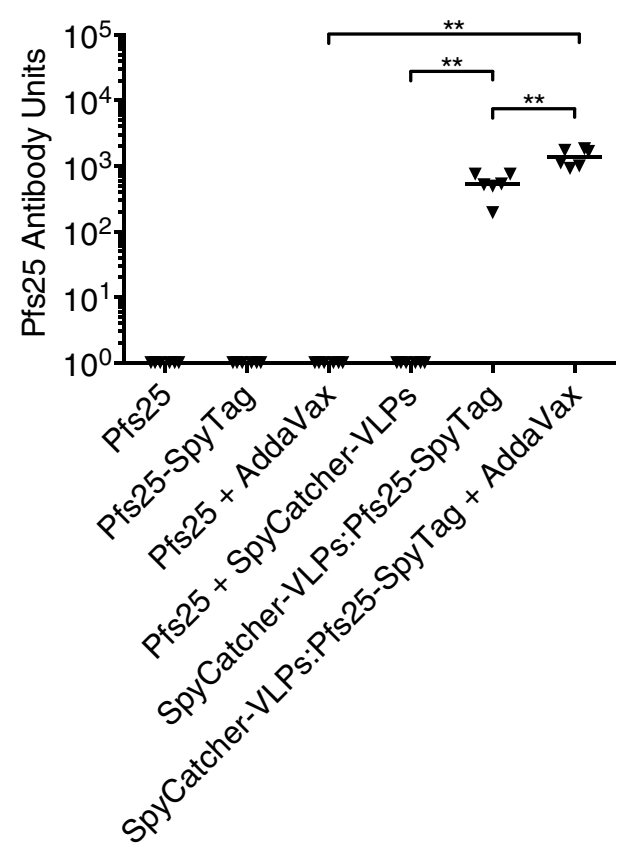

Day 34 anti-Pfs25

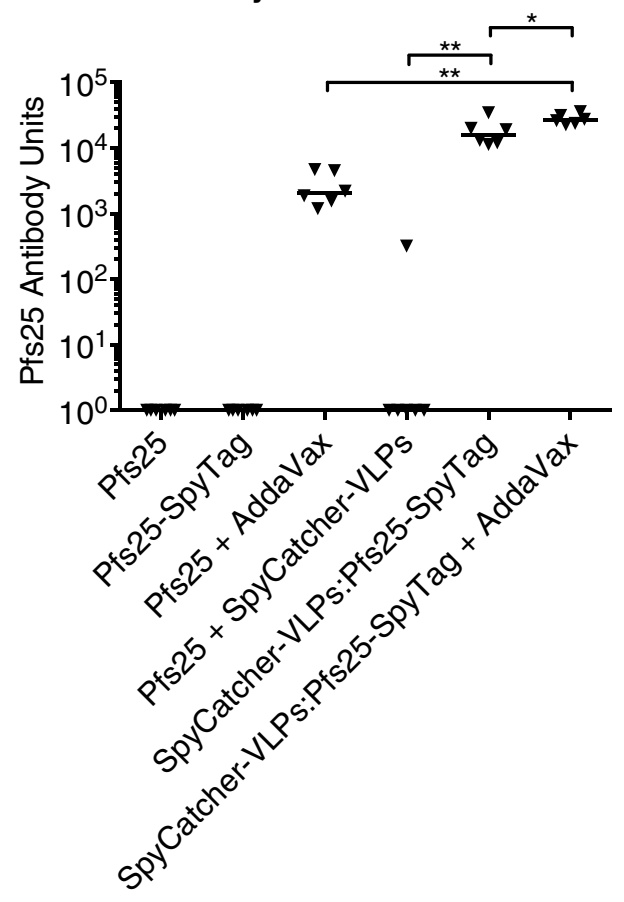

b

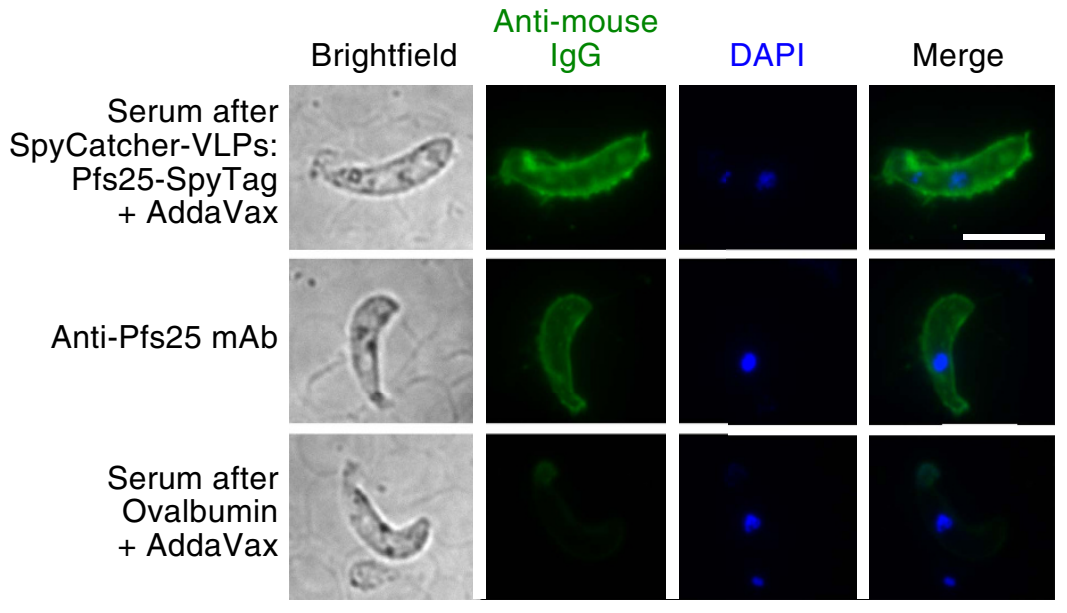

Figure 5. Plug-and-Display immunization against Pfs25. (a) Antibodies were raised to Pfs 25 after SpyCatcher-VLP immunization. 6 mice per condition were immunized on day 0 and 17 with Pfs25, Pfs25SpyTag, Pfs25-SpyTag conjugated to SpyCatcher-VLPs, or SpyCatcher-VLPs + untagged Pfs25. Where indicated, the adjuvant AddaVax was included. After prime (16 days, left) or boost (34 days, right), total antiPfs25 IgG was determined by ELISA (expressed as Pfs 25 Antibody Units, by comparison to reference serum). Triangles represent the value for each mouse, while the horizontal bar represents the median. ${ }^{*} \mathrm{p}<0.05$, ${ }^{* *} \mathrm{p}<0.01$, determined by Mann-Whitney test $(\mathrm{n}=6)$. (b) Antibodies from SpyCatcher-VLPs:Pfs25-SpyTag immunization bound the ookinete surface. Ookinetes expressing Pfs 25 were stained with day 34 serum from a mouse immunized with SpyCatcher-VLPs:Pfs25-SpyTag and AddaVax (top row). As a positive control, cells were stained with a monoclonal antibody against Pfs 25 (middle row). As a negative control, cells were stained with serum from a mouse immunized with ovalbumin and AddaVax (bottom row). Cells were visualized in the fluorescence microscope, shown with brightfield imaging (grayscale, left), antibody staining (green, center left), DAPI DNA stain (blue, center right), and an overlay of DAPI and antibody staining (right). Scale bar $=5 \mu \mathrm{m}$.

development of the parasite in the mosquito ${ }^{41,42}$. SpyTag was genetically fused to the C-terminus of Pfs 25 , before expression in mammalian cells. SpyCatcher-VLPs also reacted covalently with Pfs25-SpyTag (Fig. 3b). These results confirmed that SpyCatcher-VLPs were efficient for conjugation to protein antigens linked to SpyTag at either terminus and expressed in bacteria or eukaryotic cells.

We also tested conjugation of SpyCatcher-VLPs to solid-phase synthesized peptide antigens, in this case relevant to cancer immunity. The Telo peptide is based on a human telomerase reverse transcriptase mutant epitope, tested for immunization against a range of cancers ${ }^{43}$. The EGFRvIII peptide is derived from the cancer-specific 
epidermal growth factor receptor (EGFR) EGFRvIII mutant sequence, applied for immunization against human glioblastoma ${ }^{44}$. High yielding conjugation to SpyCatcher-VLPs was observed after incubating with SpyTag-Telo and EGFRvIII-SpyTag (Supplementary Fig. S1).

Native agarose gel electrophoresis was used to test that covalent reaction occurred while the coat protein was assembled in VLPs. Imaging of the gel showed co-migration of a distinct protein band and nucleic acid band, indicating encapsulation of nucleic acid by the hybrid SpyCatcher-VLPs (Fig. 3c). AP205 VLPs have been previously shown to encapsulate various RNAs from their expression host ${ }^{39,45}$. This SpyCatcher-VLP band was uniformly decreased in mobility by conjugation with SpyTag-CIDR(IT4var07) (Fig. 3c). As in subsequent experiments, excess antigen was simply removed from conjugated VLPs by dialysis using a high MWCO membrane.

Immunization using SpyCatcher-VLPs against CIDR. Having established the integrity and reactivity of the particles, we explored the efficiency of SpyCatcher-VLPs for generating an immune response. We focused on the immune response to CIDR(IT4var07). Mice were immunized intramuscularly with $20 \mu \mathrm{g}$ CIDR(IT4var07) equivalent, either as SpyCatcher-VLPs:SpyTag-CIDR conjugate, a negative control of SpyCatcher-VLPs + untagged CIDR, or a further negative control of CIDR alone (Fig. 4a). Reaction to form the SpyCatcher-VLPs:SpyTag-CIDR conjugate was validated by SDS-PAGE (Supplementary Fig. S2a). All immunizations were performed in the absence of adjuvant. Mice were boosted at day 14 with the same dosing regime. The antibody titer against CIDR was measured 2 weeks after each immunization (on days 13 and 28) via enzyme-linked immunosorbent assay (ELISA) (Fig. 4b). At each time-point tested, SpyCatcher-VLPs:SpyTag-CIDR induced a higher anti-CIDR response than either SpyCatcher-VLPs + untagged CIDR or the CIDR-only group (Fig. 4c). At day 13, only the SpyCatcher-VLPs:SpyTag-CIDR group showed anti-CIDR antibody generation, significantly better than with SpyCatcher-VLPs + untagged CIDR or the CIDR-only (in each case $p=0.002, n=6$, Mann-Whitney test) (Fig. 4c). After boosting, an anti-CIDR antibody response was seen in 6 of 6 mice in the SpyCatcher-VLPs:SpyTag-CIDR group, but only in 2 of 6 mice with SpyCatcher-VLPs + untagged CIDR and 4 of 6 mice with CIDR-only, indicating that, as expected, on its own CIDR is a poor immunogen (Fig. 4c). The anti-CIDR response at day 28 for the SpyCatcher-VLPs:SpyTag-CIDR group was significantly higher than the responses of the SpyCatcher-VLPs + untagged CIDR group or the CIDR-only group (in each case $\mathrm{p}=0.002$, $\mathrm{n}=6$, Mann-Whitney test) (Fig. 4c). The presence of unconjugated SpyCatcher-VLPs did not affect the immune response to CIDR (day $28 \mathrm{p}=0.3$, not significant, $n=6$, Mann-Whitney test).

To measure the immune response against the SpyCatcher-VLP platform, rather than the antigen target, we coated ELISA plates with SpyCatcher-VLPs and determined the antibody titer. As expected, mice in the SpyCatcher-VLPs:SpyTag-CIDR and SpyCatcher-VLPs + untagged CIDR groups generated an immune response to SpyCatcher-VLPs (Supplementary Fig. S3). However, this response to SpyCatcher-VLPs at day 13 was significantly lower in the SpyCatcher-VLPs:SpyTag-CIDR group than the SpyCatcher-VLPs + untagged CIDR group ( $\mathrm{p}=0.002, \mathrm{n}=6$, Mann-Whitney test). Boosting with either conjugated or unconjugated particles increased the antibody response to SpyCatcher-VLPs by approximately 1 log, but again the response in the SpyCatcher-VLPs:SpyTag-CIDR group was significantly lower than the SpyCatcher-VLPs + untagged CIDR group ( $\mathrm{p}=0.002, \mathrm{n}=6$, Mann-Whitney test) (Supplementary Fig. S3), consistent with masking of the SpyCatcher-VLP surface by the covalently conjugated CIDR.

Immunization using SpyCatcher-VLPs against Pfs25. To support further the applicability of the SpyCatcher-VLP platform, we performed immunization against Pfs25, a promising transmission-blocking antigen $^{41}$. We immunized mice intramuscularly with doses matched to $2.5 \mu \mathrm{g}$ of each version of Pfs 25 . Immunizing with Pfs25 and Pfs25-SpyTag was to test whether SpyTag itself somehow enhanced the immunogenicity of a linked antigen. These two proteins were then also injected with SpyCatcher-VLPs. Reaction of SpyCatcher-VLP with Pfs25-SpyTag for immunization was validated by SDS-PAGE (Supplementary Fig. S2b). We also tested how adjuvant affected the antibody response. AddaVax, a squalene-based oil-in-water nanoemulsion, is a potent adjuvant, reported to promote a balanced Th1/Th2 immune response and based on the MF59 adjuvant licensed for use in an influenza vaccine ${ }^{46}$. Mice were boosted at day 17 with the same dosing regime. The antibody titer against Pfs 25 was measured on days 16 and 34 via ELISA (Fig. 5a).

Pfs25 and Pfs25-SpyTag proteins alone did not give a response, even after boosting. Pfs 25 with AddaVax gave a response only after boosting. SpyCatcher-VLPs conjugated to Pfs25-SpyTag gave a strong response even before boosting, whereas the negative control of SpyCatcher-VLPs + untagged Pfs 25 gave significantly less response at day 16 or 34 (in each case $\mathrm{p}=0.002, \mathrm{n}=6$, Mann-Whitney test). Including adjuvant gave a small increase to the SpyCatcher-VLPs:Pfs25-SpyTag response after the prime $(\mathrm{p}=0.002, \mathrm{n}=6$, Mann-Whitney test $)$ and after the boost $(\mathrm{p}=0.04, \mathrm{n}=6$, Mann-Whitney test) (Fig. $5 \mathrm{a}$ ). Even with adjuvant, the response to Pfs 25 protein did not match the response to SpyCatcher-VLPs:Pfs25-SpyTag (for day 16 or 34, $\mathrm{p}=0.002, \mathrm{n}=6$, Mann-Whitney test).

To test further whether the antibodies raised from the SpyCatcher-VLP immunization could recognize native antigen, we stained a blood smear containing ookinetes expressing Pfs 25 on their surface and detected the antibody staining by fluorescence microscopy (Fig. 5b). Serum from mice boosted with SpyCatcher-VLPs:Pfs25-SpyTag and AddaVax gave strong antibody labeling on the surface of the ookinete, similar to the pattern with the validated anti-Pfs 25 monoclonal antibody $4 \mathrm{~B} 7$. As a negative control, serum from a mouse immunized with the control antigen ovalbumin and AddaVax gave minimal surface staining (Fig. 5b).

\section{Discussion}

We have established a platform for simple, rapid and stable linking of antigens to virus-like particles for immunization. We demonstrated VLP decoration with a range of malarial protein antigens and cancer-related peptides. This is consistent with the tolerance for SpyTag/SpyCatcher fusion shown by ourselves and other laboratories for applications with dendritic cell-targeting antibodies ${ }^{47}$, membrane protein imaging ${ }^{48}$, biofilms $s^{49,50}$ and hydrogels ${ }^{51}$. 
SpyCatcher-VLPs could be simply expressed from E. coli. For isolated Pfs25 protein, we required adjuvant and boosting to obtain a robust antibody response. SpyCatcher-VLPs decorated with the CIDR or Pfs 25 antigens generated a robust antibody response after only a single immunization without requiring adjuvant.

In future work it will be interesting to explore the use of SpyCatcher-SpyTag ligation for decoration of other vaccine-relevant platforms, such as norovirus and Hepatitis B virus ${ }^{3,24,52,53}$. The recently approved malaria vaccine still has only modest efficacy ${ }^{54}$ so further malaria vaccine engineering is clearly needed. It will be useful to test how the immune response from the SpyCatcher-VLP platform relates to disease protection in animal challenge models, including with promising malarial transmission-blocking antigens like Pfs $25^{41,55}$ or blood-stage antigens like $\mathrm{RH} 5^{52,56}$

SpyCatcher is derived from Streptococcus pyogenes and the coat protein is from a bacteriophage, so antibodies were raised as expected to the SpyCatcher-VLP platform, although coupling the antigen reduced this immunogenicity ${ }^{47}$. Most VLPs are immunogenic, so this is not a new issue; indeed VLP carriers can be used for repeated booster immunizations and existing antibody responses against the vaccine may even benefit vaccine immunogenicity at the time of boosting. The RTS,S malaria vaccine, based on the Hepatitis B surface antigen (HBsAg) backbone, has been given successfully three times with a booster immunization at 20 months whilst also inducing anti-HBsAg antibody responses ${ }^{57}$. This is in contrast to live viral vaccine vectors which require in situ antigen expression following infection of immunized cells; in this case anti-vector immunity impedes subsequent vector administration, meaning that different immunization platforms/vectors are required for prime versus boost ${ }^{3,52}$. Even with antibodies to SpyCatcher-VLPs present at day 13, we saw a second injection with conjugated SpyCatcher-VLPs still boosted the response to the target CIDR antigen. The Tag/Catcher principle of covalent peptide reaction has been established for a number of different pairs and so it may be possible to use these other pairs in future rounds of immunization ${ }^{58,59}$. Apart from vaccination, it will also be valuable to explore the use of Plug-and-Display nanoparticle decoration in other applications, such as drug delivery, enzyme scaffolds, biosensors, and cancer immunotherapy ${ }^{1,60,61}$.

\section{Methods}

Cloning. Expression constructs were cloned using standard PCR methods, Gibson isothermal assembly ${ }^{62}$ or In-Fusion HD Cloning Plus kit (ClonTech) and inserts were verified by Sanger sequencing. pGEM-SpyCatcher-AP205cp3 was used to generate SpyCatcher-VLPs and has the organization: N-terminal His 6 , N-terminally truncated $\Delta \mathrm{N} 1$ SpyCatcher ${ }^{34},(\mathrm{GSG})_{3}$ spacer, AP205 coat protein $3^{36}$ (codon-optimized for expression in E. coli by GeneArt) (GenBank accession number KU302810). pET28a-SpyTag-MBP and pET28a-SpyTag DA-MBP have been described ${ }^{33}$. pET15b-CIDR(IT4var07) has the organization: N-terminal $\mathrm{His}_{6}$, tobacco etch virus (TEV) cleavage site, GSG linker, $P$. falciparum CIDR(IT4var07) ${ }^{40}$. pET15b-SpyTag-CIDR(HB3var03) has SpyTag at the N-terminal side of the P. falciparum CIDR(HB3var03) ${ }^{40}$. pET15b-SpyTag-CIDR(IT4var07) has the organization: N-terminal $\mathrm{His}_{6}$, TEV cleavage site, GGS linker, SpyTag, GGS linker, P. falciparum CIDR(IT4var07, starting EPAPDVKT... $)^{40}$. pENTR4-Pfs25-SpyTag ${ }^{63}$ for expression in mammalian cells has a signal peptide from tissue plasminogen activator before $P$. falciparum Pfs25 with C-terminal SpyTag, followed by C-tag for purification ${ }^{64}$ (GenBank accession number KU302811).

pFH255, a kind gift of Ario de Marco (University of Nova Gorica), has Erv1p (sulfhydryl oxidase) and DsbC (disulfide bond isomerase) expressed under arabinose control for enhanced cytosolic formation of disulfide bonds $^{35,65}$. His $_{6}$-TEV protease expression vector was a kind gift of the Stephen Bottomley laboratory, Monash University, and has the organization: MBP-TEV_site-His 6 -TEV_protease (L56V, S135G, S219V)-R ${ }_{5}{ }^{66}$.

Expression of SpyCatcher-VLPs. C41 E. coli ${ }^{67}$, a kind gift of Anthony Watts (University of Oxford), was transformed with pGEM-SpyCatcher-AP205cp3 and pFH255 and plated on LB-Lennox $(5 \mathrm{~g} / \mathrm{L} \mathrm{NaCl})$ agar plates with $100 \mu \mathrm{g} / \mathrm{mL}$ ampicillin and $34 \mu \mathrm{g} / \mathrm{mL}$ chloramphenicol. The plates were incubated at $37^{\circ} \mathrm{C}$ for $16-20 \mathrm{~h} .4$ entire colonies were picked into $400 \mathrm{~mL}$ LB-Lennox medium with $20 \mu \mathrm{g} / \mathrm{mL}$ ampicillin and $34 \mu \mathrm{g} / \mathrm{mL}$ chloramphenicol in a $2 \mathrm{~L}$ strongly-baffled glass flask and incubated without shaking for $10-14 \mathrm{~h}$ at $37^{\circ} \mathrm{C}$. The culture was then diluted 1:1 with fresh media (final concentration $20 \mu \mathrm{g} / \mathrm{mL}$ ampicillin, $17 \mu \mathrm{g} / \mathrm{mL}$ chloramphenicol assuming that all previous ampicillin was degraded overnight) and incubated with shaking at $120 \mathrm{rpm}$ (Infors Multitron, $2.5 \mathrm{~cm}$ throw) at $37^{\circ} \mathrm{C}$ for $1 \mathrm{~h}$, before induction at $\mathrm{A} 6000.9$ with $1 \mathrm{mM} \mathrm{IPTG}$ for $6-8 \mathrm{~h}$ at $37^{\circ} \mathrm{C}$, shaking at $180 \mathrm{rpm}$.

Purification of VLPs. One $1,000 \mathrm{~mL}$ culture-derived pellet (typically 12 in total) was washed in $50 \mathrm{~mL}$ ice-cooled PBS and spun for $10 \mathrm{~min}$ at $4,000 \mathrm{~g}$ at $4{ }^{\circ} \mathrm{C}$. The pellet was resuspended at RT in $10 \mathrm{~mL}$ lysis buffer: $20 \mathrm{mM}$ Tris $\bullet \mathrm{HCl}, 150 \mathrm{mM} \mathrm{NaCl}, 0.1 \%$ (v/v) Triton X-100, $0.1 \%$ (v/v) Tween 20, pH 7.8. The resuspended mixture was incubated at RT for $15 \mathrm{~min}$, placed in an ice-salt water bath for $10 \mathrm{~min}$ and then sonicated 4 times for $30 \mathrm{~s}$, with a minimum of $1 \mathrm{~min}$ between each pulse. The lysates were spun twice at $15,000 \mathrm{~g}$ for $20 \mathrm{~min}$ at $4{ }^{\circ} \mathrm{C}$. The supernatant was filtered using a $1.2 \mu \mathrm{m}$ glass filter device (Sartorius) and then through a $0.45 \mu \mathrm{m}$ surfactant-free cellulose acetate filter device (Nalgene). $250 \mathrm{U}$ benzonase (Sigma) was added and the mixture incubated for $5 \mathrm{~min}$ at RT. Ni-NTA elution buffer ( $50 \mathrm{mM}$ Tris $\bullet \mathrm{HCl}, 300 \mathrm{mM} \mathrm{NaCl}, 1 \mathrm{M}$ imidazole, $\mathrm{pH}$ 7.8) was then added to a final concentration of $75 \mathrm{mM}$ imidazole. $1 \mathrm{~mL}$ of packed Ni-NTA agarose (Qiagen) was added to the cleared lysate. The tubes were incubated on a rotary shaker for $10 \mathrm{~min}$ at $4{ }^{\circ} \mathrm{C}$ and then centrifuged for $2 \mathrm{~min}$ at $4,700 \mathrm{~g}, 4^{\circ} \mathrm{C}$. The resin was washed three times in $100 \mathrm{mM}$ imidazole washing buffer. The supernatant was then aspirated and the remaining resin was once more added to the cleared lysate imidazole-conditioned solution, the process repeated and finally resuspended in $15 \mathrm{~mL} 100 \mathrm{mM}$ NTA-buffer. $5 \mathrm{~mL}$ each were transferred to a $15 \mathrm{~mL}$ Falcon tube (3 in total) and each tube was topped up to $15 \mathrm{~mL}$ with $100 \mathrm{mM}$ washing buffer containing $0.1 \%(\mathrm{v} / \mathrm{v})$ Triton X-114 (TX114), to remove endotoxin ${ }^{68}$. Two more washes with full volume TX114, $100 \mathrm{mM}$ imidazole were applied, prior to three washes without TX114. The sample was resuspended and applied to a polyprep column. For elution, 
the polyprep column was capped, $2.5 \mathrm{~mL}$ of elution buffer [ $2 \mathrm{M}$ imidazole, $50 \mathrm{mM}$ glycine, $25 \mathrm{mM}$ sodium citrate, $0.1 \%(\mathrm{v} / \mathrm{v})$ Tween 20, $\mathrm{pH} 8.5$ ] added and the resin incubated on a mini shaker (900 rpm) for $10 \mathrm{~min}$ at RT prior to elution. The eluate was once more cleared over a mini polyprep column (Bio-Rad) to remove any agarose resin. The flow-through in $1.5 \mathrm{~mL}$ centrifuge tubes was spun for $10 \mathrm{~min}$ at $4^{\circ} \mathrm{C}$ at $17,000 \mathrm{~g}$, pipetted into a $300 \mathrm{kDa}$ MWCO cellulose ester dialysis tubing (SpectrumLabs) and dialyzed overnight at $4{ }^{\circ} \mathrm{C}$ against 1,000 -fold excess of $50 \mathrm{mM}$ glycine, $25 \mathrm{mM}$ sodium citrate, $0.1 \%$ (v/v) Tween $20, \mathrm{pH} 8.0$ for buffer exchange and to deplete species such as VLP monomer. Dialysis was repeated in fresh buffer for an additional $3 \mathrm{~h}$. After dialysis, the sample was spun once more at $17,000 \mathrm{~g}$ for $10 \mathrm{~min}$ at $4^{\circ} \mathrm{C}$, to remove any aggregate.

Expression of CIDR proteins. ClearColi BL21(DE3) (Lucigen), which have mutated lipopolysaccharide for low endotoxin protein production ${ }^{69}$, was transformed with the plasmid pSC101 argU ileY leuW StrepR/SpecR from BL21-CodonPlus(DE3)-RIPL (Agilent) and $\mathrm{pFH} 255$. The bacteria were plated onto $34 \mu \mathrm{g} / \mathrm{mL}$ chloramphenicol and $60 \mu \mathrm{g} / \mathrm{mL}$ streptomycin, yielding ClearColi BL21(DE3)-RIL-dsbC-erv1p. Single colonies were obtained after $\sim 36 \mathrm{~h}$ and $\mathrm{CaCl}_{2}$-competent cells were prepared. pET15b-CIDR(IT4var07), pET15b-SpyTag-CIDR(HB3var03) or pET15b-SpyTag-CIDR(IT4var07) was transformed into ClearColi BL21(DE3)-RIL-dsbC-erv1p and selected on LB-Miller $(10 \mathrm{~g} / \mathrm{L} \mathrm{NaCl}), 34 \mu \mathrm{g} / \mathrm{mL}$ chloramphenicol, $100 \mu \mathrm{g} / \mathrm{mL}$ ampicillin. Singe colonies (visible after 36-48 h) were inoculated into LB-Miller $100 \mu \mathrm{g} / \mathrm{mL}$ ampicillin, $20 \mu \mathrm{g} / \mathrm{mL}$ chloramphenicol, $30 \mu \mathrm{g} / \mathrm{mL}$ streptomycin for $15 \mathrm{~h}$ at $37^{\circ} \mathrm{C}$ with shaking at $180 \mathrm{rpm}$ with $2.5 \mathrm{~cm}$ throw. The cultures were diluted 1:100 into $750 \mathrm{~mL}$ LB in $2 \mathrm{~L}$ strongly baffled glass flasks (Scientific Laboratory Supplies), grown to A600 0.6, induced with $2.5 \mathrm{~g}$ arabinose, except for pET15b-SpyTag-CIDR(HB3var03), grown as before until A600 0.7-1.0 and then induced with $1 \mathrm{mM}$ IPTG for $12-14 \mathrm{~h}$ at $22^{\circ} \mathrm{C}$, shaking at $250 \mathrm{rpm}$ prior to harvest.

Purification of CIDRs. Each cell pellet was resuspended in $12 \mathrm{~mL}$ lysis buffer: $20 \mathrm{mM}$ Tris $\bullet \mathrm{HCl}, 300 \mathrm{mM}$ $\mathrm{NaCl}, 15 \mathrm{mM}$ imidazole, $0.5 \%$ (v/v) Triton X-100, $10 \%$ (v/v) glycerol, $1 \mathrm{mg} / \mathrm{mL}$ lysozyme (Sigma), and $2 \mathrm{U} /$ $\mathrm{mL}$ benzonase $\mathrm{pH}$ 8.0. The sample was sonicated on ice using $4 \times 30 \mathrm{~s}$ pulses, with 1 min rest between each pulse. The insoluble fraction was spun down at 27,000 $g$ at $4{ }^{\circ} \mathrm{C}$. For pET15b-CIDR(IT4var07) and pET15b-SpyTag-CIDR(IT4var07), the soluble protein in the supernatant was purified using standard Ni-NTA as above, with washing at $30 \mathrm{mM}$ imidazole and elution at $200 \mathrm{mM}$ imidazole. pET15b-SpyTag-CIDR(HB3var03) was purified from inclusion bodies, as described ${ }^{40}$. Briefly, inclusion bodies were resuspended in guanidinium hydrochloride, bound to Ni-NTA and refolded on resin with decreasing guanidinium concentration. Protein was then eluted with Ni-NTA elution buffer $\left(200 \mathrm{mM}\right.$ imidazole, $20 \mathrm{mM}$ Tris $\bullet \mathrm{HCl}, 300 \mathrm{mM} \mathrm{NaCl}, \mathrm{pH}$ 8.0). $\mathrm{His}_{6}$-TEV protease $^{66}$ purified in redox buffer $(20 \mathrm{mM}$ Tris $\bullet \mathrm{HCl}, 300 \mathrm{mM} \mathrm{NaCl}, 3 \mathrm{mM}$ reduced glutathione, $0.3 \mathrm{mM}$ oxidised glutathione, $\mathrm{pH}$ 8.0) from ClearColi BL21(DE3)-RIPL $\mathrm{His}_{6}$-TEV was added at 1:100 A280 equivalents to protein derived from pET15b-CIDR(IT4var07) and pET15b-SpyTag-CIDR(IT4var07). TEV protease digestion to remove the N-terminal $\mathrm{His}_{6}$ tag for ELISA was performed in the presence of redox buffer for $4 \mathrm{~h}$ at $30^{\circ} \mathrm{C}$. The processed eluate was then dialyzed twice at $4^{\circ} \mathrm{C}$ against 1,000 -fold excess $20 \mathrm{mM}$ Tris $\bullet \mathrm{HCl}, 300 \mathrm{mM} \mathrm{NaCl}, \mathrm{pH} 7.8$ with a $3.5 \mathrm{kDa}$ cut-off membrane (Fisher Scientific) and applied to $0.5 \mathrm{~mL}$ of binding buffer $(20 \mathrm{mM} \mathrm{Tris} \bullet \mathrm{HCl}$, $150 \mathrm{mM} \mathrm{NaCl}, \mathrm{pH}$ 7.8) equilibrated Ni-NTA resin to capture uncleaved protein, $\mathrm{His}_{6}$-TEV protease and cleaved $\mathrm{His}_{6}$-tag. The flow-through was then concentrated to a final volume of $1 \mathrm{~mL}$ using $3.5 \mathrm{kDa}$ MWCO spin filter (GE Healthcare) and applied to a HiLoad 16/600 Superdex 75 pg column (GE Healthcare). The column was equilibrated with 1.5 column-volumes of column buffer ( $20 \mathrm{mM}$ HEPES, $\mathrm{pH} 7.5,500 \mathrm{mM} \mathrm{NaCl}$ ) at $1 \mathrm{~mL} / \mathrm{min}$. The prep was analyzed by SDS-PAGE and desirable fractions concentrated to $10-15 \mathrm{mg} / \mathrm{mL}$, prior to storage at $-80^{\circ} \mathrm{C}$.

Expression of Pfs25-SpyTag. Suspension HEK293E cells were cultured to 2 million cells/mL in Expi293 Expression Medium (Life Technologies) containing penicillin/streptomycin at $37^{\circ} \mathrm{C}$ and $8 \% \mathrm{CO}_{2}$ at $125 \mathrm{rpm}$. Cells were transiently transfected with $1 \mu \mathrm{g}$ plasmid complexed to polyethylenimine per million cells. Supernatant was harvested after $72 \mathrm{~h}$. Pfs25-SpyTag was purified by CaptureSelect C-tag Affinity Matrix (Life Technologies) using the manufacturer's instructions, followed by size-exclusion chromatography (HiLoad 16/600 Superdex 200 pg column, GE Healthcare).

SpyCatcher-VLP:SpyTag-protein interaction. SpyTag-MBP and SpyTag DA-MBP were expressed in E. coli and purified by Ni-NTA as previously described ${ }^{33}$. SpyCatcher-VLPs were reacted with $1.5 \times$ molar excess of SpyTag interaction partner in a total volume of $150 \mu \mathrm{L}$ including $15 \mu \mathrm{L}$ of $10 \times$ reaction buffer $\left(40 \mathrm{mM} \mathrm{Na}_{2} \mathrm{HPO}_{4}\right.$, $200 \mathrm{mM}$ sodium citrate, $\mathrm{pH}$ 6.2); if the volume of SpyCatcher-VLPs and SpyTag-partner did not amount to $150 \mu \mathrm{L}$ or no partner was added for the control, the difference in volume was topped up with $20 \mathrm{mM} \mathrm{Tris} \bullet \mathrm{HCl}$, $300 \mathrm{mM} \mathrm{NaCl}$, pH 7.8. Protein concentrations for partners were: SpyTag-MBP, $82.5 \mu \mathrm{M}$; SpyTag DA-MBP, $87 \mu \mathrm{M}$; SpyTag-CIDR(HB3var03), 144.3 $\mu$ M; SpyTag-CIDR(IT4var07, TEV cleaved), 263.5 $\mu$ M; Pfs25-SpyTag, 59 $\mu$ M. The reaction was performed for $3 \mathrm{~h}$ at RT and stopped with $6 \times$ SDS-PAGE loading buffer [ $20 \%$ glycerol, $100 \mathrm{mM}$ Tris• $\mathrm{HCl}, 4 \%$ SDS, $0.2 \%$ bromophenol blue, $1 \%(\mathrm{v} / \mathrm{v}) 2$-mercaptoethanol, $\mathrm{pH} 6.8$ ] and subsequent heating for $3 \mathrm{~min}$ at $95^{\circ} \mathrm{C}$.

Peptides. Peptides were synthesized by Insight Biotechnology at $>95 \%$ purity, validated by HPLC and mass spectrometry. SpyTag-Telo is SpyTag linked to a human telomerase reverse transcriptase mutant epitope implicated with increased risk of various cancers ${ }^{43}$ (biotin-GAHIVMVDAYKPTREARPALLTSRLRFIPK). SpyTag-Telo was dissolved at $100 \mathrm{mg} / \mathrm{mL}$ in a 2:1 mixture of $\mathrm{H}_{2} \mathrm{O}$ to acetic acid. Stock solution was diluted 10-fold with $50 \mathrm{mM}$ glycine, $25 \mathrm{mM}$ sodium citrate, $0.1 \%$ (v/v) Tween 20 , pH 8.0 buffer, prior to conjugation. EGFRvIII-SpyTag contains the fusion junction epitope of human epidermal growth factor receptor (EGFR) found in glioblastoma ${ }^{44}$ (LEEKKGNYVVTDHGAHIVMVDAYKPTK-biotin). This peptide was dissolved at $100 \mathrm{mg} / \mathrm{mL}$ in a 1:4 mixture of formic acid to $\mathrm{H}_{2} \mathrm{O}$. EGFRvIII-SpyTag stock was diluted 10 -fold with $10 \times$ reaction buffer $\left(40 \mathrm{mM} \mathrm{Na}_{2} \mathrm{HPO}_{4}\right.$, $200 \mathrm{mM}$ sodium citrate, $\mathrm{pH} 6.2$ ), prior to conjugation. 
SpyCatcher-VLP:SpyTag-peptide reaction. SpyCatcher-VLPs were expressed and purified as before, except washing was with NTA buffer $(50 \mathrm{mM}$ Tris $\bullet \mathrm{HCl}, 300 \mathrm{mM} \mathrm{NaCl}, \mathrm{pH} 7.8,0.1 \%$ v/v Tween 20) plus $200 \mathrm{mM}$ imidazole and elution was with NTA buffer plus $2 \mathrm{M}$ imidazole. No dialysis was performed prior to reaction. SpyCatcher-VLPs at $2.9 \mathrm{mg} / \mathrm{mL}$ were mixed with a $2.4 \times$ molar excess of SpyTag-Telo or a $2.7 \times$ molar excess of EGFRvIII-SpyTag (as compared to the concentration of SpyCatcher moieties). After addition of $10 \times$ reaction buffer $\left(40 \mathrm{mM} \mathrm{Na}_{2} \mathrm{HPO}_{4}, 200 \mathrm{mM}\right.$ sodium citrate, $\mathrm{pH}$ 6.2), the sample was incubated for $3 \mathrm{~h}$ at $22^{\circ} \mathrm{C}$. To control for any change in the buffer altering the gel mobility of SpyCatcher-VLPs, the "Solvent control" sample contained SpyCatcher-VLPs mixed for $3 \mathrm{~h}$ at RT with a solution matching the solvent concentration of the peptide sample (acetic acid for SpyTag-Telo or formic acid for EGFRvIII-SpyTag), with no reaction buffer added. The "Solvent + Rxn control" sample was the same as the "Solvent control" sample, except that phosphate-citrate reaction buffer was included. The reaction was stopped by adding $6 \times$ SDS-PAGE loading buffer and heating for 3 min at $95^{\circ} \mathrm{C}$. Samples were analyzed by $14 \%$ SDS-PAGE with Coomassie staining.

SDS-PAGE. SDS-PAGE was performed on 12\% Tris-glycine gels using an XCell SureLock system (Life Technologies) unless otherwise indicated. Gels were stained with InstantBlue (Expedeon) and imaged using a ChemiDoc XRS imager and QuantityOne (version 4.6) software (Bio-Rad).

Protein concentrations were determined using a bicinchoninic acid assay (Pierce ${ }^{\mathrm{TM}}$ BCA Protein Assay Kit, Thermo Scientific), following manufacturer's instructions without the use of reducing agent.

Size-exclusion chromatography (SEC). VLPs ( $5 \mathrm{~mL}$ at A280 7) eluted from Ni-NTA resin were applied to a previously equilibrated HiPrep 16/60 Sephacryl S-500 HR (GE Healthcare) on a fast protein liquid chromatography (FPLC) system Purifier 10 (GE Healthcare). The mobile-phase column buffer was $20 \mathrm{mM}$ Tris $\bullet \mathrm{HCl}, 1 \mathrm{M}$ $\mathrm{NaCl}, \mathrm{pH} 8.5$ and the applied flow-rate was $1.0 \mathrm{~mL} / \mathrm{min}$, all at $4^{\circ} \mathrm{C}$. For calibration, a high molecular weight gel filtration standard (Bio-Rad) was used.

Agarose gel electrophoresis. A 1\% (w/v) agarose gel, prepared in $40 \mathrm{mM}$ Tris, $20 \mathrm{mM}$ acetic acid, $1 \mathrm{mM}$ EDTA, pH 8.0, containing $1 \times$ SybrSafe (Life Technologies) according to manufacturer's instruction was loaded with $20 \mu \mathrm{L}$ SpyCatcher-VLPs, with or without $30 \mu \mathrm{M}$ SpyTag-CIDR(IT4var07) conjugation, after mixing with DNA loading buffer. DNA loading buffer was $0.15 \mathrm{~g} / \mathrm{mL}$ Ficoll 400 (Sigma), $40 \mathrm{mM}$ Tris, $20 \mathrm{mM}$ acetic acid, $1 \mathrm{mM}$ EDTA, pH 8.0 supplemented with Orange G (Sigma). The samples were run for $1 \mathrm{~h}$ at $120 \mathrm{~V}(7.7 \mathrm{~V} / \mathrm{cm})$ in TAE ( $40 \mathrm{mM}$ Tris, $20 \mathrm{mM}$ acetic acid, $1 \mathrm{mM}$ EDTA, pH 8.0). First SybrSafe was imaged on a UV table equipped with an XcitaBlue ${ }^{\mathrm{TM}}$ screen kit for excitation with blue light. Then the gel was stained with a Coomassie-based dye, InstantBlue, and imaged with visible light illumination using a ChemiDoc XRS imager and QuantityOne (version 4.6) software.

Transmission electron microscopy (TEM). $\quad 10 \mu \mathrm{L}$ SpyCatcher-VLPs $(0.2 \mathrm{mg} / \mathrm{mL})$ were applied to freshly glow-discharged carbon 200 mesh copper grids for 2 min, blotted with filter paper, and stained with $2 \%$ uranyl acetate for $10 \mathrm{~s}$, then blotted and air dried. Grids were imaged in a FEI Tecnai T12 transmission electron microscope at $120 \mathrm{kV}$ using a Gatan US1000 CCD camera. Particle diameter for each group was measured with FIJI (ImageJ) with $2 \mathrm{~nm}$ bin size $(\mathrm{n}=100)$.

Preparation of immunogens. For CIDR immunization, SpyCatcher-VLPs $(30 \mu \mathrm{M})$ were incubated with $1.5 \times$ molar excess of SpyTag-CIDR (IT4var07, TEV cleaved to remove $\mathrm{His}_{6}$-tag) for $3 \mathrm{~h}$ at RT with addition of $10 \times$ reaction buffer $\left(40 \mathrm{mM} \mathrm{Na}_{2} \mathrm{HPO}_{4}, 200 \mathrm{mM}\right.$ sodium citrate, $\left.\mathrm{pH} 6.2\right)$. The reaction volume was then dialyzed with $300 \mathrm{kDa}$ cut-off membrane twice against 1,000-fold excess PBS with $0.1 \%(\mathrm{v} / \mathrm{v})$ Tween 20 to remove unreacted SpyTag-CIDR. Doses were matched to $20 \mu \mathrm{g}$ CIDR(IT4var07)-equivalent for the SpyCatcher-VLPs + untagged CIDR(IT4var07) group and the CIDR(IT4var07)-alone group and diluted with sterile endotoxin-free PBS (Life Technologies) with $0.1 \%$ (v/v) Tween 20 to a total of $50 \mu \mathrm{L}$ per dose. Two individual batches prepared within $24 \mathrm{~h}$ prior to immunization were $0.22 \mu \mathrm{m}$-filtered, using autoclaved polyvinylidene difluoride (PVDF) membrane (Whatman).

Endotoxin concentrations were determined with Pierce LAL Chromogenic Endotoxin Quantitation Kit (Thermo Fisher Scientific) following manufacturer's instructions and were below 1 Endotoxin Unit/mL for SpyCatcher-VLP preparations.

For Pfs 25 immunization, SpyCatcher-VLPs $(30 \mu \mathrm{M})$ were incubated with $1.5 \times$ molar excess of Pfs25-SpyTag for $3 \mathrm{~h}$ at $\mathrm{RT}$ with addition of $10 \times$ reaction buffer $\left(40 \mathrm{mM} \mathrm{Na}_{2} \mathrm{HPO}_{4}, 200 \mathrm{mM}\right.$ sodium citrate, $\left.\mathrm{pH} 6.2\right)$. The reaction was then dialyzed with $300 \mathrm{kDa}$ cut-off membrane three times against 1,000-fold excess $50 \mathrm{mM}$ glycine, $25 \mathrm{mM}$ sodium citrate, $0.1 \%(\mathrm{v} / \mathrm{v})$ Tween 20 to remove unreacted Pfs25-SpyTag. Doses were matched to $2.5 \mu \mathrm{g}$ Pfs 25 equivalent for each group and diluted with sterile $50 \mathrm{mM}$ glycine, $25 \mathrm{mM}$ sodium citrate, $0.1 \%(\mathrm{v} / \mathrm{v})$ Tween 20 to a total of $50 \mu \mathrm{L}$ per dose or $25 \mu \mathrm{L}$ per dose in groups containing adjuvant. Adjuvanted groups were mixed 1:1 with stock AddaVax (InvivoGen, distributed by Source BioScience) with gentle pipetting and kept on ice until immunization within $2 \mathrm{~h}$. An AddaVax adjuvanted negative control group for microscopy was prepared in the same manner, replacing Pfs 25 with ovalbumin as the immunogen.

Immunizations. Animal experiments and procedures were performed according to the UK Animals (Scientific Procedures) Act Project License (PPL 30/2414 and 30/2889) and approved by the Oxford University Local Ethical Review Body. Age-matched ( 60 days old at first immunization) female BALB/c mice (Harlan, UK), housed in specific-pathogen free environments, were injected intramuscularly with protein sample into each rear leg using a protein prime-boost regime. Protein samples for injection were prepared in sterile endotoxin-free PBS (Thermo Fisher Scientific) with $0.1 \%$ (v/v) Tween 20. Mice received the priming dose on day 0, followed by a boosting dose on the indicated day. Blood samples were taken to obtain sera for endpoint ELISA. Sera were 
obtained from whole blood by leaving samples overnight at $4{ }^{\circ} \mathrm{C}$ to clot, followed by 5 min centrifugation at $16,000 \mathrm{~g}$ in a benchtop centrifuge at RT. Sera were pipetted into fresh Eppendorf tubes with care not to disturb the pellet. 6 mice were used per condition.

Endpoint ELISA. Nunc-Immuno MaxiSorp plates (Thermo Scientific) were coated with $100 \mu \mathrm{L} /$ well of CIDR(IT4var07) or SpyCatcher-VLP at $1 \mu \mathrm{g} / \mathrm{mL}$ in coating buffer ( $15 \mathrm{mM}$ sodium carbonate with $35 \mathrm{mM}$ sodium bicarbonate) overnight at $4{ }^{\circ} \mathrm{C}$. Plates were washed with PBS/T (PBS supplemented with $0.5 \%$ Tween 20 ) and blocked for $1 \mathrm{~h}$ at RT with $10 \%$ skimmed milk in PBS/T. Serum samples were added in duplicates and diluted 3-fold down the plate, followed by incubation for $2 \mathrm{~h}$ at RT and then washed with PBS/T as before. Goat anti-mouse total IgG conjugated to alkaline phosphatase (Sigma-Aldrich) was added to the plate (1:3,000 dilution in PBS/T) for $1 \mathrm{~h}$ at RT. After a final wash in PBS/T, p-nitrophenylphosphate (Sigma-Aldrich) diluted in diethanolamine buffer (1 M diethanolamine, $\mathrm{pH}$ 9.8) (Thermo Scientific) was used as a developing substrate. A405 was obtained using an ELx800 absorbance microplate reader (Biotek). The endpoint titer is defined as the x-axis intercept of the dilution curve at an absorbance value ( \pm 3 s.d.) greater than the A405 for a serum sample from a mouse immunized with an irrelevant protein control, Pfs25-nanoparticle from a previous experiment.

ELISA against Pfs 25 was performed according to a standardized protocol using a reference serum, as described previously ${ }^{70}$. Nunc-Immuno MaxiSorp plates were coated with Pfs 25 protein at $0.1 \mu$ g per well in PBS/T overnight at RT. Plates were washed with PBS/T and blocked for $1 \mathrm{~h}$ with $5 \%$ skimmed milk in PBS/T at RT. Test serum samples were diluted in PBS/T and $100 \mu \mathrm{L}$ of each were added to the relevant well, followed by incubation for $2 \mathrm{~h}$ at RT, and then washing with PBS/T six times at RT. Donkey anti-mouse total IgG conjugated to alkaline phosphatase (Jackson ImmunoResearch Laboratories) was added to the plate (1:3,000 dilution in PBS) for $1 \mathrm{~h}$ at RT. After a final wash in PBS/T, samples were developed with p-nitrophenylphosphate and measured as described above. All samples were tested against a serially-diluted standard reference serum with a known antibody titer, prepared as described previously ${ }^{71}$. The absorbance of individual test samples was converted into Pfs 25 Antibody Units using a standard curve generated by this standard reference serum as described ${ }^{70}$.

Statistical analysis of immunizations. Statistical analyses were performed using GraphPad Prism. Continuous variables between two groups were compared by a two-tailed Mann-Whitney test.

Immunofluorescence. Immunofluorescence was performed on ookinetes fixed with paraformaldehyde (PFA) as described previously ${ }^{63}$. Ookinete culture smears of Pfs25DR3 transgenic Plasmodium berghei parasite (a chimeric P. berghei line which expresses Pfs25 in place of the endogenous Pbs25, provided by Dr Andrew Blagborough, Imperial College London) were fixed for $10 \mathrm{~min}$ in PBS with $4 \%$ PFA at RT, followed by washing in PBS. Slides were blocked for $1 \mathrm{~h}$ in PBS with 3\% (w/v) BSA at RT, followed by incubation for $45 \mathrm{~min}$ with $2 \mu \mathrm{g} / \mathrm{mL}$ anti-Pfs 25 monoclonal antibody 4B7 72 (a kind gift from Kazutoyo Miura, National Institutes of Health, Maryland, USA) or test antiserum (1:100, from mice primed and boosted with AddaVax and SpyCatcher-VLPs:Pfs25-SpyTag or Ovalbumin) in PBS with 3\% (w/v) BSA at RT in a humidified chamber. Slides were washed three times in PBS and then incubated with AlexaFluor 488-conjugated goat anti-mouse IgG (1:500) (Thermo Fisher Scientific) in PBS with 3\% (w/v) BSA at RT for $45 \mathrm{~min}$. After another three washes with PBS, slides were mounted with mounting medium with DAPI (Vector Laboratories), allowed to set overnight at $4{ }^{\circ} \mathrm{C}$ and analyzed by wide-field fluorescence microscopy on a DMI3000 B microscope (Leica Microsystems). All samples were stained, imaged and analyzed under the same conditions.

\section{References}

1. Sapsford, K. E. et al. Functionalizing Nanoparticles with Biological Molecules: Developing Chemistries that Facilitate Nanotechnology. Chem. Rev. 113, 1904-2074 (2013).

2. De Gregorio, E. \& Rappuoli, R. From empiricism to rational design: a personal perspective of the evolution of vaccine development. Nat. Rev. Immunol. 14, 505-514 (2014).

3. Draper, S. J. \& Heeney, J. L. Viruses as vaccine vectors for infectious diseases and cancer. Nat. Rev. Microbiol. 8, 62-73 (2010),

4. Marston, H. D., Folkers, G. K., Morens, D. M. \& Fauci, A. S. Emerging Viral Diseases: Confronting Threats with New Technologies. Sci. Transl. Med. 6, 1-6 (2014).

5. Smith, D. M., Simon, J. K. \& Baker Jr, J. R. Applications of nanotechnology for immunology. Nat. Rev. Immunol. 13, 592-605 (2013).

6. Bachmann, M. F. \& Jennings, G. T. Vaccine delivery: a matter of size, geometry, kinetics and molecular patterns. Nat. Rev. Immunol. 10, 787-796 (2010)

7. Hua, Z. \& Hou, B. TLR signaling in B-cell development and activation. Cell. Mol. Immunol. 10, 103-106 (2013).

8. Zabel, F., Kündig, T. M. \& Bachmann, M. F. Virus-induced humoral immunity: on how B cell responses are initiated. Curr. Opin. Virol. 3, 357-362 (2013).

9. Roldão, A., Mellado, M. C. M., Castilho, L. R., Carrondo, M. J. T. \& Alves, P. M. Virus-like particles in vaccine development. Expert Rev. Vaccines 9, 1149-1176 (2010).

10. Jain, N. K. et al. Formulation and stabilization of recombinant protein based virus-like particle vaccines. Adv. Drug Deliv. Rev. 93, 42-55 (2014).

11. Schiller, J. T. \& Müller, M. Next generation prophylactic human papillomavirus vaccines. Lancet Oncol. 16, e217-e225 (2015).

12. Bachmann, M. F. \& Whitehead, P. Active immunotherapy for chronic diseases. Vaccine 31, 1777-1784 (2013).

13. Ratsimandresy, R. A., Rappaport, J. \& Zagury, J.-F. Anti-cytokine therapeutics: history and update. Curr. Pharm. Des. 15, 1998-2025 (2009).

14. Patel, J. M. et al. Influenza virus-like particles engineered by protein transfer with tumor-associated antigens induces protective antitumor immunity. Biotechnol. Bioeng. 112, 1102-1110 (2015).

15. Smith, M. T., Hawes, A. K. \& Bundy, B. C. Reengineering viruses and virus-like particles through chemical functionalization strategies. Curr. Opin. Biotechnol. 24, 620-626 (2013).

16. Mateu, M. G. Virus engineering: functionalization and stabilization. Protein Eng. Des. Sel. 24, 53-63 (2011).

17. Walker, A., Skamel, C. \& Nassal, M. SplitCore: An exceptionally versatile viral nanoparticle for native whole protein display regardless of 3D structure. Sci. Rep. 1, 5 (2011).

18. Mascola, J. R. \& Montefiori, D. C. The Role of Antibodies in HIV Vaccines. Annu. Rev. Immunol. 28, 413-444 (2010). 
19. Sletten, E. M. \& Bertozzi, C. R. Bioorthogonal Chemistry: Fishing for Selectivity in a Sea of Functionality. Angew. Chem. Int. Ed. 48, 6974-6998 (2009).

20. Jegerlehner, A. et al. A molecular assembly system that renders antigens of choice highly repetitive for induction of protective B cell responses. Vaccine 20, 3104-3112 (2002).

21. Pattenden, L. K., Middelberg, A. P. J., Niebert, M. \& Lipin, D. I. Towards the preparative and large-scale precision manufacture of virus-like particles. Trends Biotechnol. 23, 523-529 (2005).

22. Anelli, T. et al. Thiol-mediated protein retention in the endoplasmic reticulum: the role of ERp44. EMBO J. 22, 5015-5022 (2003).

23. Baneyx, F. \& Mujacic, M. Recombinant protein folding and misfolding in Escherichia coli. Nat. Biotechnol. 22, 1399-1408 (2004).

24. Koho, T. et al. His-tagged norovirus-like particles: A versatile platform for cellular delivery and surface display. Eur. J. Pharm. Biopharm. 96, 22-31 (2015).

25. Tong, G. J., Hsiao, S. C., Carrico, Z. M. \& Francis, M. B. Viral Capsid DNA Aptamer Conjugates as Multivalent Cell-Targeting Vehicles. J. Am. Chem. Soc. 131, 11174-11178 (2009).

26. Strable, E. \& Finn, M. G. In Viruses and Nanotechnology (eds. Manchester, M. \& Steinmetz, N. F.) 327, 1-21 (Springer Berlin Heidelberg, 2009).

27. Patel, K. G. \& Swartz, J. R. Surface Functionalization of Virus-Like Particles by Direct Conjugation Using Azide-Alkyne Click Chemistry. Bioconjug. Chem. 22, 376-387 (2011).

28. Sasmal, P. K. et al. Catalytic azide reduction in biological environments. Chembiochem 13, 1116-1120 (2012).

29. van den Bosch, S. M. et al. Evaluation of strained alkynes for Cu-free click reaction in live mice. Nucl. Med. Biol. 40, 415-423 (2013).

30. Versteegen, R. M., Rossin, R., ten Hoeve, W., Janssen, H. M. \& Robillard, M. S. Click to Release: Instantaneous Doxorubicin Elimination upon Tetrazine Ligation. Angew. Chem. Int. Ed. 52, 14112-14116 (2013).

31. Aerni, H. R., Shifman, M. A., Rogulina, S., O'Donoghue, P. \& Rinehart, J. Revealing the amino acid composition of proteins within an expanded genetic code. Nucleic Acids Res. 43, e8 (2015).

32. Veggiani, G., Zakeri, B. \& Howarth, M. Superglue from bacteria: unbreakable bridges for protein nanotechnology. Trends Biotechnol. 32, 506-512 (2014)

33. Zakeri, B. et al. Peptide tag forming a rapid covalent bond to a protein, through engineering a bacterial adhesin. Proc. Natl. Acad. Sci. 109, E690-E697 (2012).

34. Li, L., Fierer, J. O., Rapoport, T. A. \& Howarth, M. Structural analysis and optimization of the covalent association between SpyCatcher and a peptide Tag. J. Mol. Biol. 426, 309-317 (2014).

35. Veggiani, G. \& de Marco, A. Improved quantitative and qualitative production of single-domain intrabodies mediated by the coexpression of Ervlp sulfhydryl oxidase. Protein Expr. Purif. 79, 111-114 (2011).

36. Klovins, J., Overbeek, G. P., van den Worm, S. H. E. van den, Ackermann, H.-W. \& van Duin, J. Nucleotide sequence of a ssRNA phage from Acinetobacter: kinship to coliphages. J. Gen. Virol. 83, 1523-1533 (2002).

37. Tissot, A. C. et al. Versatile virus-like particle carrier for epitope based vaccines. PloS One 5, e9809 (2010).

38. van den Worm, S. H. E., Koning, R. I., Warmenhoven, H. J., Koerten, H. K. \& van Duin, J. Cryo electron microscopy reconstructions of the Leviviridae unveil the densest icosahedral RNA packing possible. J. Mol. Biol. 363, 858-865 (2006).

39. Spohn, G. et al. A VLP-based vaccine targeting domain III of the West Nile virus E protein protects from lethal infection in mice. Virol. J. 7, $146(2010)$.

40. Lau, C. K. Y. et al. Structural conservation despite huge sequence diversity allows EPCR binding by the PfEMP1 family implicated in severe childhood malaria. Cell Host Microbe 17, 118-129 (2015).

41. Nikolaeva, D., Draper, S. J. \& Biswas, S. Toward the development of effective transmission-blocking vaccines for malaria. Expert Rev. Vaccines 14, 653-680 (2015).

42. Li, Y. et al. Enhancing immunogenicity and transmission-blocking activity of malaria vaccines by fusing Pfs 25 to IMX313 multimerization technology. Sci. Rep. in press, SREP-15-24347A, (2015).

43. Kokhaei, P. et al. Telomerase (hTERT 611-626) serves as a tumor antigen in B-cell chronic lymphocytic leukemia and generates spontaneously antileukemic, cytotoxic T cells. Exp. Hematol. 35, 297-304 (2007).

44. Gedeon, P. C., Choi, B. D., Sampson, J. H. \& Bigner, D. D. Rindopepimut. Drugs Future 38, 147 (2013).

45. Freivalds, J. et al. Yeast-expressed bacteriophage-like particles for the packaging of nanomaterials. Mol. Biotechnol. 56, 102-110 (2014).

46. Mbow, M. L., De Gregorio, E., Valiante, N. M. \& Rappuoli, R. New adjuvants for human vaccines. Curr. Opin. Immunol. 22, 411-416 (2010).

47. Liu, Z. et al. A novel method for synthetic vaccine construction based on protein assembly. Sci. Rep. 4, 7266 (2014).

48. Bedbrook, C. N. et al. Genetically Encoded Spy Peptide Fusion System to Detect Plasma Membrane-Localized Proteins In Vivo. Chem. Biol. 22, 1108-1121 (2015).

49. Chen, A. Y. et al. Synthesis and patterning of tunable multiscale materials with engineered cells. Nat. Mater. 13, 515-523 (2014).

50. Botyanszki, Z., Tay, P. K. R., Nguyen, P. Q., Nussbaumer, M. G. \& Joshi, N. S. Engineered catalytic biofilms: Site-specific enzyme immobilization onto E. coli curli nanofibers. Biotechnol. Bioeng. 112, 2016-2024 (2015).

51. Sun, F., Zhang, W.-B., Mahdavi, A., Arnold, F. H. \& Tirrell, D. A. Synthesis of bioactive protein hydrogels by genetically encoded SpyTag-SpyCatcher chemistry. Proc. Natl. Acad. Sci. 111, 11269-11274 (2014).

52. Douglas, A. D. et al. A PfRH5-Based Vaccine Is Efficacious against Heterologous Strain Blood-Stage Plasmodium falciparum Infection in Aotus Monkeys. Cell Host Microbe 17, 130-139 (2015).

53. Rampling, T. et al. A Monovalent Chimpanzee Adenovirus Ebola Vaccine-Preliminary Report. N. Engl. J. Med. doi: 10.1056/ NEJMoa1411627 (2015).

54. RTS, S. Clinical Trials Partnership et al. A phase 3 trial of RTS,S/AS01 malaria vaccine in African infants. N. Engl. J. Med. 367, 2284-2295 (2012).

55. Kapulu, M. C. et al. Comparative Assessment of Transmission-Blocking Vaccine Candidates against Plasmodium falciparum. Sci. Rep. 5, 11193 (2015).

56. Wright, K. E. et al. Structure of malaria invasion protein RH5 with erythrocyte basigin and blocking antibodies. Nature 515, $427-430$ (2014).

57. RTS, S. Clinical Trials Partnership. Efficacy and safety of RTS,S/AS01 malaria vaccine with or without a booster dose in infants and children in Africa: final results of a phase 3, individually randomised, controlled trial. Lancet 386, 31-45 (2015).

58. Zakeri, B. \& Howarth, M. Spontaneous Intermolecular Amide Bond Formation between Side Chains for Irreversible Peptide Targeting. J. Am. Chem. Soc. 132, 4526-4527 (2010).

59. Kang, H. J. \& Baker, E. N. Intramolecular isopeptide bonds: protein crosslinks built for stress? Trends Biochem. Sci. 36, 229-237 (2011).

60. Jennings, G. T. \& Bachmann, M. F. Immunodrugs: therapeutic VLP-based vaccines for chronic diseases. Annu. Rev. Pharmacol. Toxicol. 49, 303-326 (2009).

61. Delamarre, L., Mellman, I. \& Yadav, M. Neo approaches to cancer vaccines. Science 348, 760-761 (2015).

62. Gibson, D. G. et al. Enzymatic assembly of DNA molecules up to several hundred kilobases. Nat. Methods 6, 343-345 (2009).

63. Goodman, A. L. et al. A viral vectored prime-boost immunization regime targeting the malaria Pfs 25 antigen induces transmissionblocking activity. PloS One 6, e29428 (2011).

64. Pardon, E., Steyaert, J. \& Wyns, L. Epitope Tag for Affinity-Based Applications. EU Patent Application EP2576609 filed 01 Dec. 2011. 
65. Nguyen, V. D. et al. Pre-expression of a sulfhydryl oxidase significantly increases the yields of eukaryotic disulfide bond containing proteins expressed in the cytoplasm of E.coli. Microb. Cell Factories 10, 1 (2011).

66. Cabrita, L. D. et al. Enhancing the stability and solubility of TEV protease using in silico design. Protein Sci. 16, 2360-2367 (2007).

67. Miroux, B. \& Walker, J. E. Over-production of proteins in Escherichia coli: mutant hosts that allow synthesis of some membrane proteins and globular proteins at high levels. J. Mol. Biol. 260, 289-298 (1996).

68. Zimmerman, T. et al. Simultaneous metal chelate affinity purification and endotoxin clearance of recombinant antibody fragments. J. Immunol. Methods 314, 67-73 (2006).

69. Mamat, U. et al. Detoxifying Escherichia coli for endotoxin-free production of recombinant proteins. Microb. Cell Factories 14, 57 (2015).

70. Miura, K. et al. Development and characterization of a standardized ELISA including a reference serum on each plate to detect antibodies induced by experimental malaria vaccines. Vaccine 26, 193-200 (2008).

71. Wu, Y. et al. Sustained high-titer antibody responses induced by conjugating a malarial vaccine candidate to outer-membrane protein complex. Proc. Natl. Acad. Sci. 103, 18243-18248 (2006).

72. Barr, P. J. et al. Recombinant Pfs 25 protein of Plasmodium falciparum elicits malaria transmission-blocking immunity in experimental animals. J. Exp. Med. 174, 1203-1208 (1991).

\section{Acknowledgements}

The authors gratefully acknowledge Errin Johnson (Bioimaging Facility, Sir William Dunn School of Pathology, University of Oxford) for assistance with TEM, Matthew Higgins (Department of Biochemistry, University of Oxford) for CIDR plasmids, Yves Durocher (CNRC-NRC, Canada) for provision of HEK293E cells, and Aadil El-Turabi (Jenner Institute, University of Oxford) for helpful advice on VLPs. Funding was provided by Oxford University Department of Biochemistry (K.D.B. and M.H.). S.J.D. is a Jenner Investigator, Lister Institute Research Prize Fellow and a Wellcome Trust Senior Fellow (grant number 106917/Z/15/Z). S.B. is a Nuffield Department of Medicine Leadership Fellow and Junior Research Fellow of St. Catherine's College, Oxford University.

\section{Author Contributions}

K.D.B. performed all experiments, except D.B.L. performed immunizations and ELISAs and I.J.B. performed immunofluorescence. A.S.I. generated unique protein antigens. K.D.B., D.B.L., I.J.B., M.F.B., S.J.D., S.B. and M.H. designed the experiments. K.D.B. and M.H. wrote the paper. All authors analyzed the data.

\section{Additional Information}

Supplementary information accompanies this paper at http://www.nature.com/srep

Competing financial interests: M.H. is an inventor on a patent regarding peptide targeting via spontaneous amide bond formation (EP2534484).

How to cite this article: Brune, K. D. et al. Plug-and-Display: decoration of Virus-Like Particles via isopeptide bonds for modular immunization. Sci. Rep. 6, 19234; doi: 10.1038/srep19234 (2016).

(c) (i) This work is licensed under a Creative Commons Attribution 4.0 International License. The images or other third party material in this article are included in the article's Creative Commons license, unless indicated otherwise in the credit line; if the material is not included under the Creative Commons license, users will need to obtain permission from the license holder to reproduce the material. To view a copy of this license, visit http://creativecommons.org/licenses/by/4.0/ 